\title{
Sistema de Coleta de Dados para Microbalanças de Quartzo
}

\section{Data Acquisition System for Quartz Crystal Microbalances}

\author{
Kleber Romero Felizardo ${ }^{1}$
}

\begin{abstract}
Resumo
Este trabalho apresenta um sistema de coleta de dados utilizado em um sensor de massa: microbalança de quartzo. Este sistema realiza a leitura em freqüência deste sensor ao longo do tempo e envia os dados coletados ao computador através de uma interface serial.

Palavras-chaves: Sistema de coleta de dados. Microbalança de quartzo. Microcontrolador.
\end{abstract}

\begin{abstract}
This work presents a data acquisition system used in a mass sensor: quartz crystal microbalance. This system reads the frequency of this sensor along the time and sends the collected data to the computer through a serial interface.
\end{abstract}

Key words: Data Acquisition System. Quartz crystal microbalance. Microcontroller.

\footnotetext{
${ }^{1}$ Mestre em Engenharia Elétrica, Professor colaborador do Dept ${ }^{\circ}$ de Engenharia Elétrica da Universidade Estadual de Londrina. E-mail:klerfe@uel.br
} 


\section{Introdução}

Uma microbalança de quartzo é um material do tipo piezelétrico e pode ser utilizada como um sensor de gás (massa), capaz de efetuar medidas de variação de massa da ordem de nanogramas baseado na variação de sua frequiência de ressonância (HIDEHITO, 2000; YUWONO; LAMMERS, 2004).

A microbalança de quartzo é formada por uma fina lâmina de cristal de quartzo, corte AT, fixada por dois eletrodos metálicos para contato elétrico. Sua lâmina de quartzo é revestida com um filme fino. $\mathrm{O}$ uso de diversos tipos de filmes finos sobre a face do cristal de quartzo introduz uma seletividade ao sensor de massa, sendo utilizado para induzir uma adsorção seletiva de certos gases de interesse quando em contato com este filme fino (CHANG; HIROSHI; MIYAKE, 2000). Quando a microbalança de quartzo adsorve este gás, ocorre um incremento de massa na superfície do cristal e, como conseqüência, temos um desvio na freqüência de ressonância do cristal. Para converter variações de massa em variações de frequiência, é necessário a construção de osciladores estáveis para a microbalança de quartzo.

Esta relação entre o desvio na freqüência de ressonância de uma microbalança de quartzo e sua variação de massa é dada pela relação de Sauerbrey (NAKAMURA; NAKAMOTO; MORIIZUMI, 2000).

$$
\Delta f_{m}=f_{m}-f_{c}=-\left(\frac{2 \cdot f_{c}^{2}}{A \cdot \sqrt{\mu_{c} \cdot \rho_{c}}}\right) \cdot \Delta m
$$

Na equação (1), $\Delta f_{m}[\mathrm{~Hz}]$ é o desvio na freqüência ocorrido na microbalança devido à alteração em $f_{m}[\mathrm{~Hz}], f_{m}$ simboliza a alteração que ocorre na freqüência de ressonância do cristal quando ocorre variação de massa $\Delta m$ [g] em sua superfície, $A\left[\mathrm{~cm}^{2}\right]$ é a área da face do cristal onde é feita a deposição dos filmes finos, $\mu_{c}\left[\mathrm{~g} / \mathrm{cm} . \mathrm{s}^{2}\right]$ e $\rho_{c}$ [g/ $\mathrm{cm}^{3}$ ] são, respectivamente, o módulo de cisalhamento e a densidade do cristal de quartzo e $f_{c}$ é a freqüência de ressonância do cristal. O sinal negativo da equação 1 indica que um aumento de massa provoca um decremento em $f_{m}$. Consequentemente, o valor do desvio de frequiência de ressonância $\Delta f_{m}$ torna-se mais negativo, uma vez que $f_{c}$ é uma constante.

O processo de coleta de dados da microbalança de quartzo é realizado ao longo do tempo por meio da leitura da diferença de frequiência $\left(\Delta f_{m}\right)$ entre a microbalança de quartzo $\left(f_{m}\right)$ e o cristal de referência $\left(f_{c}\right)$. Para que se possa ler esta diferença de frequiência, o sistema deve ser dotado de um circuito misturador digital, cuja finalidade é obter diretamente o valor da diferença de freqüência entre dois sinais digitais. O cristal de referência possui a mesma frequiência de ressonância da microbalança de quartzo e encontra-se nas mesmas condições ambientais. A diferença entre ambos é que o cristal de referência não recebeu a deposição do filme fino em sua face, não alterando sua frequiência quando em contato com a amostra gasosa. Portanto, não sofre variações em sua freqüência de ressonância devido ao fator massa. Os cristais de quartzo têm a sua freqüência fundamental alterado com a mudança de temperatura. Se ambos, a microbalança de quartzo e o cristal de quartzo estão nas mesmas condições de temperatura, ambos irão sofrer o mesmo desvio na freqüência devido ao fator temperatura. Este desvio de freqüência causado pela temperatura será eliminado pelo circuito misturador. Desse modo, o efeito da temperatura é minimizado.

$\mathrm{Na}$ maioria das vezes, a leitura do sinal das microbalanças de quartzo é medida com freqüencímetros digitais com interface a um computador. Porém, a utilização de sistemas microcontrolados é uma alternativa mais barata e compacta. Neste trabalho, o sistema de coleta de dados foi implementado com um microcontrolador da família 8051. As medidas da diferença de freqüência entre a microbalança de quartzo e o cristal de referência foram enviadas a um computador por meio de uma porta serial, via interface RS-232 (FELIZARDO, 2005). 


\section{Materiais e Métodos}

O sistema de coleta de dados utilizado neste trabalho é esquematizado no diagrama de blocos mostrado na Figura 1.

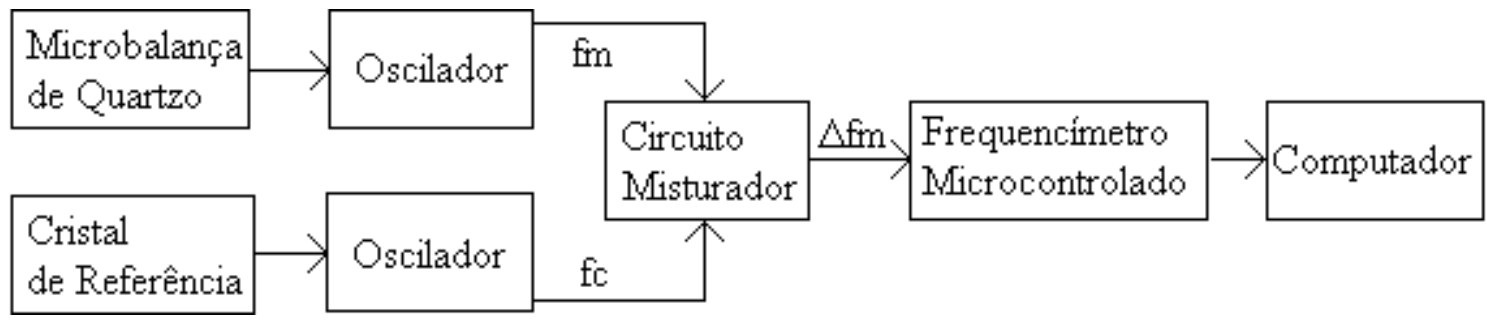

Figura 1. Sistema de Coleta de Dados (FELIZARDO, 2005).

Tanto a microbalança de quartzo como o cristal de referência são conectados ao seu respectivo circuito oscilador, obtendo desta maneira variações em frequiência ao longo do tempo. A diferença de freqüência entre a microbalança de quartzo $\left(f_{m}\right)$ e o cristal de referência $\left(f_{C}\right)$ é realizada pelo circuito misturador digital, e seu objetivo é obter a diferença de freqüência entre estes dois sinais. Esta diferença de frequiência, por sua vez, é lida por meio de um freqüencímetro microcontrolado e enviada ao computador, para posterior análise dos dados coletados, através de uma interface serial. Os blocos apresentados na Figura 1 são discutidos a seguir.

\section{O circuito Oscilador}

Os osciladores utilizados na microbalança de quartzo e no cristal de referência é o oscilador do tipo Pierce com portas lógicas. Este oscilador é muito utilizado devido à sua fácil implementação (com poucos componentes) e alta estabilidade em uma ampla faixa de frequiências (até aproximadamente $30 \mathrm{MHz}$ ) (RAMON; WEBSTER, 2000; CHOW; HSU; CHEN, 2002). Os osciladores estão mostrados na Figura 2. O uso de dois inversores cascateados na saída dos osciladores atua como um buffer de sinal.

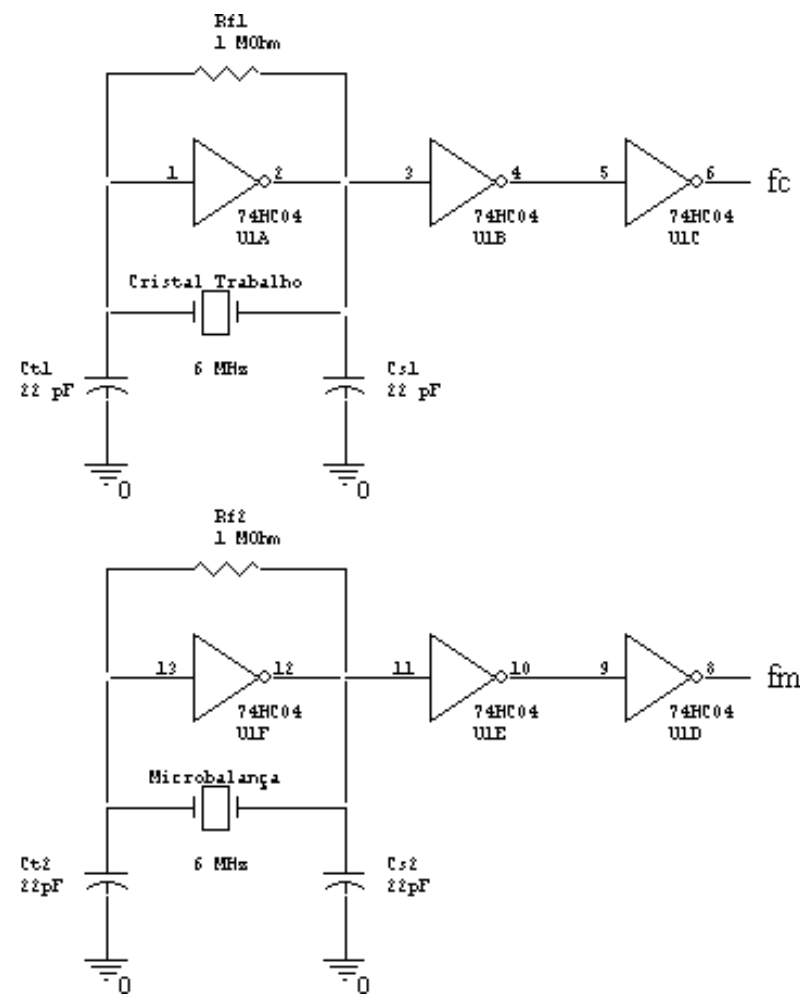

Figura 2. Osciladores do tipo Pierce utilizados na microbalança de quartzo e no cristal de referência (FELIZARDO, 2005).

Os capacitores de disco cerâmico de 100nF, os quais devem estar conectados o mais próximo possível dos terminais de alimentação de todos os componentes integrados, para que se possa eliminar eventuais picos espúrios e ruídos esses componentes, não foram incluídos nos esquemáticos elétricos, apesar do seu uso neste trabalho. 
A Microbalança de Quartzo e o Cristal de Referência

Neste experimento, foi utilizada uma microbalança de quartzo, manufaturada com cristal de quartzo comercial de $6 \mathrm{MHz}$, de corte AT, recoberta com filme fino de polidifenilamina, como elemento sensível ao álcool etílico. O cristal de referência utilizado possui a mesma freqüência fundamental da microbalança de quartzo. A diferença entre ambos é que o cristal de referência não foi recoberto com o filme fino, ou seja, teve apenas seu invólucro metálico retirado (FELIZARDO, 2005).

\section{O Circuito Misturador}

Um circuito misturador formado por um flip-flop tipo D (74HC74) encarregou-se de realizar a diferença de frequiências entre a microbalança de quartzo e o cristal de referência. Desse modo, variações de freqüência ocorridas em ambos os cristais devido ao fator temperatura são minimizadas quando é realizada a subtração entre as duas freqüências (CHAMBI, 1998; ZHANGI; GAO, 1997; DOSSIL, 1999). O uso deste misturador também torna mais simples a transmissão do sinal e a implementação de um contador de pulsos (realizado pelo microcontrolador), já que a faixa de valores da diferença de freqüência entre a microbalança de quartzo e o cristal de referência não ultrapassa algumas dezenas de $\mathrm{kHz}$. O circuito misturador adotado neste trabalho é mostrado na Figura 3.

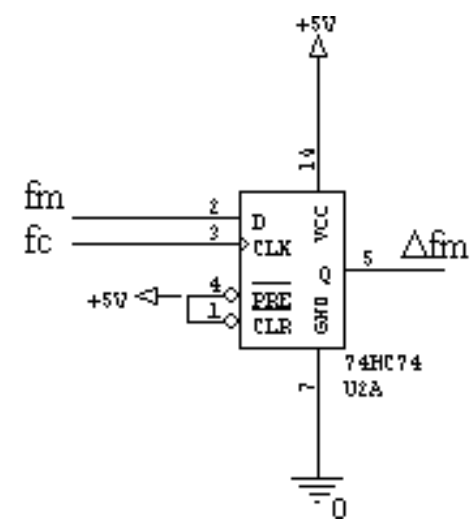

Figura 3. O circuito misturador digital (FELIZARDO, 2005).

\section{O Freqüencímetro Microcontrolado}

Para a medida do desvio de freqüência da microbalança de quartzo e o cristal de referência $\left(\Delta f_{m}\right)$, foi utilizado um freqüencímetro microcontrolado com interface RS232, utilizando o microcontrolador AT89C2051 (fabricante ATMEL). Este freqüencímetro microcontrolado é capaz de efetuar medidas de 0 a $65 \mathrm{kHz}$ com precisão de $1 \mathrm{~Hz}$ a cada 1s. Os dados coletados são enviados ao computador utilizando-se o protocolo de comunicação 8N1 (1 bit de start, 8 bits de dados, sem paridade, 1 bit de stop e baud-rate de 9600). Este freqüencímetro é mostrado na Figura 4.

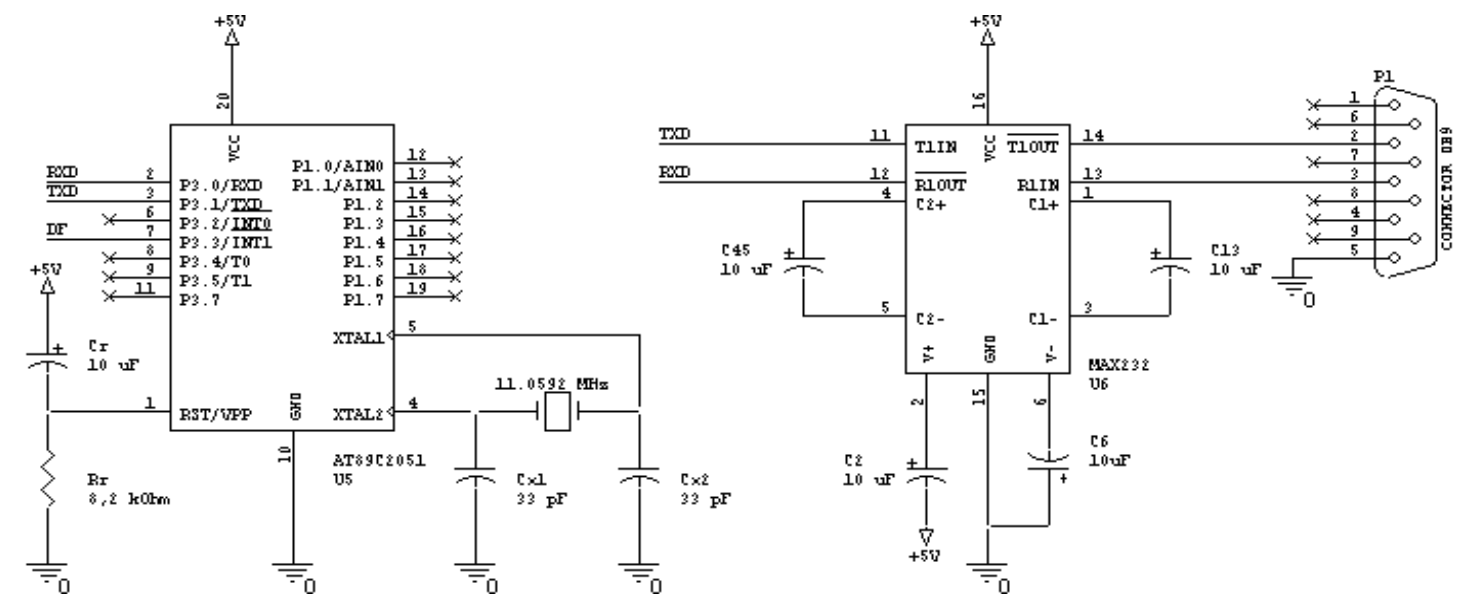

Figura 4. Freqüencímetro microcontrolado com interface serial (FELIZARDO, 2005). 
Para transformar os níveis TTL/CMOS do canal serial do microcontrolador (pinos RXD e TXD) nos níveis padrões RS232 foi utilizado o circuito integrado MAX232.

O fluxograma do programa do microcontrolador, escrito em linguagem Assembler, pode ser visto na Figura 5. Após o reset do microcontrolador, todos seus registradores internos são configurados para desempenhar suas funções corretamente. Neste caso, o registrador TIMER0 é configurado para gerar a base de tempo de 1s, o registrador INT1 é configurado para gerar interrupções a cada borda de descida detectada no pino P3.3 e o registrador TIMER 1 é configurado para gerar uma taxa da serial de $9600 \mathrm{bps}$. Após a configuração, é feita a leitura da freqüência $\Delta f_{m}$ contando o número de pulsos ocorrido no pino P3.3 durante 1s. Esta contagem é armazenada no registrador de 16 bits, DPTR, capaz de armazenar até $2^{16}=65535$ contagens. $O$ valor armazenado em DPTR é exatamente o valor da frequiência lido no pino P3.3. Após a contagem dos pulsos, o resultado armazenado no registrador DPTR é convertido para o formato hexadecimal no padrão ASCII e é enviado pela porta serial do microcontrolador para uma porta serial do computador, na taxa de 9600 bps e utilizando o protocolo $8 \mathrm{~N} 1$.

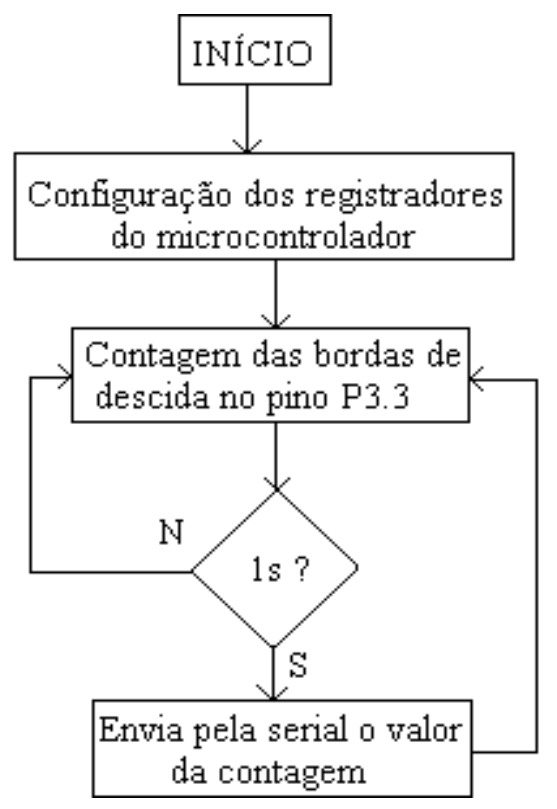

Figura 5. O fluxograma do programa do microcontrolador (FELIZARDO, 2005).

\section{O computador}

Os dados enviados pelo microcontrolador foram recebidos pela porta serial do computador através do software Hyperterminal, disponível em qualquer sistema operacional Windows. Dessa maneira, os dados coletados foram salvos em um arquivo tipo texto, através do modo de captura de texto do software Hyperterminal.

Os dados coletados são convertidos do padrão hexadecimal para decimal e recebem uma filtragem digital. A filtragem digital é necessária para que o ruído presente no sinal seja minimizado, suavizando deste modo à curva de resposta da microbalança. $\mathrm{O}$ filtro utilizado é um filtro de média móvel de ordem 3 , atuando como um filtro passa-baixa.

\section{Resultados e Conclusões}

A Figura 6 mostra o resultado de uma coleta de dados durante 1000 segundos (FELIZARDO, 2005).

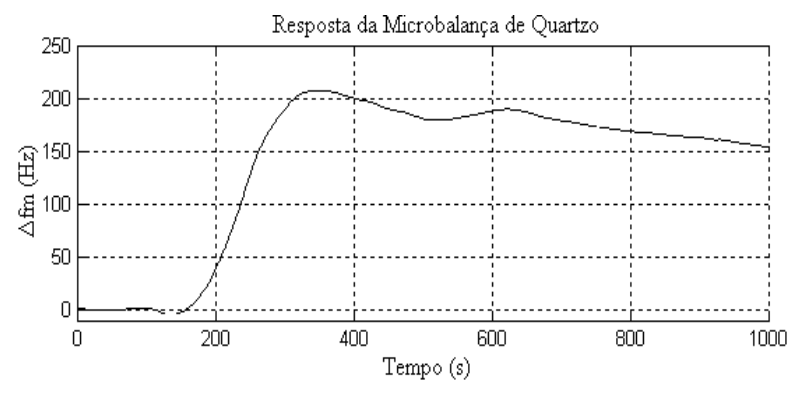

Figura 6. Resultado experimental de uma coleta de dados da microbalança de quartzo quando exposta ao álcool etílico (FELIZARDO, 2005).

Pode-se observar que, durante os 180 primeiros segundos, o desvio de frequiência $\Delta f_{m}$ é bem próximo de zero, pois a microbalança de quartzo não foi exposta ao vapor de álcool etílico. Passado este período de tempo, a microbalança de quartzo foi exposta ao vapor de álcool (quantidade de $60 \mu \mathrm{L}$ ). Neste momento, ocorre um aumento de massa na superfície do cristal proveniente da adsorção do vapor de álcool pelo filme fino depositado na superfície do cristal, ocorrendo, portanto um desvio de freqüência. À medida que a concentração de vapor de álcool vai ficando menor, devido ao processo de desorção, a quantidade de massa na superfície do filme fino vai ficando menor 
e a resposta da microbalança de quartzo vai tendendo novamente a zero. Nesta fase, já não existe a presença de álcool tanto no ambiente em que a microbalança de quartzo se encontra tanto na superfície do filme fino. Pelo gráfico da Figura 6, podemos observar que o desvio máximo da microbalança é da ordem de $=200 \mathrm{~Hz}$.

Outros resultados podem ser vistos na Figura 7. Pode-se verificar, por meio dos gráficos das Figuras 6 e 7, que o sistema foi capaz de realizar a coleta de dados a cada 1s, mantendo a precisão de $1 \mathrm{~Hz}$ em suas medidas. O limite da leitura de frequiência de até $65 \mathrm{kHz}$ foi mais do que suficiente, uma vez que o desvio de frequiência entre a microbalança de quartzo e o cristal de referência não ultrapassou a faixa de 1 $\mathrm{kHz}$.

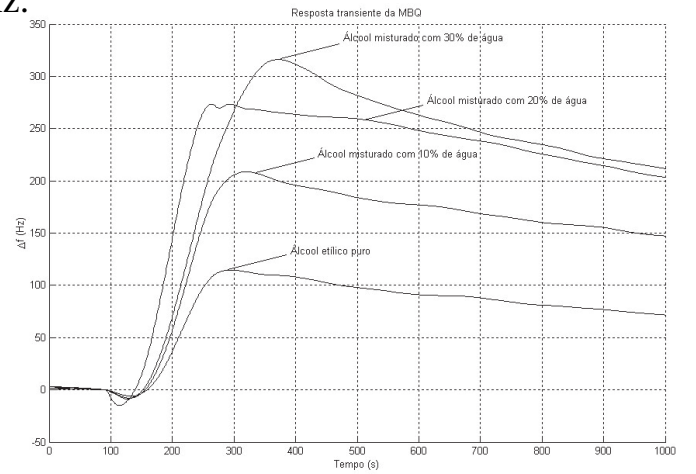

Figura 7. Resultados experimentais de várias coletas de dados da microbalança de quartzo quando exposta a diferentes concentrações de álcool etílico (FELIZARDO, 2005).

Este sistema de coleta de dados representa uma alternativa barata e compacta para sua utilização em microbalanças de quartzo, uma vez que dispensa o uso de equipamentos caros, como o frequiencímetro digital com interface para o computador, equipamento utilizado no sistema de coleta de dados envolvendo microbalanças de quartzo.

\section{Referências}

CHAMBI, R. C. Desenvolvimento de uma microbalança de quartzo para detectar gases. 1998. Tese (Mestrado) - Escola Politécnica da Universidade de São Paulo, São Paulo.

CHANG, S. M.; HIROSHI, M.; MIYAKE, J. The principle and applications of piezoelectric crystal sensors. Materials Science and Engineering $C$, Lausanne, v.12, n.1/2, p.111-123, aug. 2000.
CHOW, S. F.; HSU, W. L.; CHEN, C. Y. Development of and immunosensor for human ferritin, nonspecific tumor marker based on a quartz crystal microbalance. Analytica Chimica Acta, Amsterdam, v.453, p.181-189, 2002.

DE JESUS, P. J.; MEDEIROS, G. A.; DO LAGO, C. L. Desenvolvimento de um detector piezelétrico para cromatógrafo a gás interfaceado a microcomputador. Química Nova, São Paulo, v.22, p.151-155, 1999.

FELIZARDO, K. R. Identificação de amostras de álcool etílico e água com uma microbalança de quartzo e redes neurais artificiais. 2005. Tese (Mestrado) Universidade Estadual de Londrina, Londrina.

HIDEHITO, N.; YOKOI, Y.; MUKAI, T.; DOUGUICHI, Y. Novel gas sensor using polymerfilm-coated quartz resonator for environmental monitoring. Materials Science and Engineering C, Lausanne, v.12, p.43-48, 2000.

NAKAMURA, $\quad$ K.; $\quad$ NAKAMOTO,$\quad$ T.; MORIIZUMI, T. Classification and evaluation of sensing films for QCM odor sensors by steady-state sensor response measurement. Sensors and Actuators B, Lausanne, v.69, n.3, p.295-301, oct. 2000.

RAMON, P. A.; WEBSTER, J. G. John G. Sensors and signal conditioning. New York: John Wiley \& Sons, Inc., 2000.

ZHANG, C.; GAO, Z. Development of a new kind of dual modulated QCM biosensor. Biosensors and Bioelectronics, Inglaterra, v.12, n.12, p.1219-1225, dec. 1997.

YUWONO, A. S.; LAMMERS, P. S. Odor pollution in the environment and the detection instrumentation. Journal of Scientific Research and Development, USA, v.6, jul. 2004. Invited Overview Paper. 